\title{
Reexamining the Impact of Industrial Structure on Haze Pollution Based on the Yangtze River Delta
}

\author{
Lu Wang ${ }^{1}$, Shumin Jiang ${ }^{1, *(1)}$ and Hua $\mathrm{Xu}^{2}$ \\ 1 School of Mathematical Sciences, Jiangsu University, No.301, Xuefu Road, Zhenjiang 212013, China; \\ 2211902026@stmail.ujs.edu.cn \\ 2 Taizhou College, Nanjing Normal University, No.96, Jichuandong Road, Taizhou 225300, China; \\ 2111802005@stmail.ujs.edu.cn \\ * Correspondence: jsm@ujs.edu.cn; Tel.: +86-137-7554-4897
}

Citation: Wang, L.; Jiang, S.M.; Xu,

$H$. Reexamining the Impact of

Industrial Structure on Haze

Pollution Based on the Yangtze River Delta. Atmosphere 2021, 12, 613.

https://doi.org/10.3390/atmos 12050613

Academic Editor: Rajasekhar

Balasubramanian

Received: 12 March 2021

Accepted: 2 May 2021

Published: 9 May 2021

Publisher's Note: MDPI stays neutral with regard to jurisdictional claims in published maps and institutional affiliations.

Copyright: (C) 2021 by the authors Licensee MDPI, Basel, Switzerland. This article is an open access article distributed under the terms and conditions of the Creative Commons Attribution (CC BY) license (https:/ / creativecommons.org/licenses/by/ $4.0 /)$.

\begin{abstract}
In this study, the static and dynamic spatial Durbin model between industrial structure and haze pollution in Yangtze River Delta is constructed. Later, the spatial spillover effect and time lag effect of haze pollution in Yangtze River Delta are analyzed. The impact of rationalization and upgrading of industrial structure on haze pollution and its spatial spillover effect are discussed. The results show that: (i) PM2.5 has a significant positive spatial spillover effect and time lag effect; (ii) in the short run, the rationalization and upgrading of industrial structure has no inhibitory effect on haze pollution, while the rationalization and upgrading of industrial structure of surrounding cities has an inhibitory effect on local haze pollution; (iii) in the long run, the rationalization and upgrading of industrial structure of surrounding cities have an inhibitory effect on local haze pollution; (iv) economic growth, FDI, the number of Industrial Enterprises above Designated Size, and population density also have spatial spillover effects on haze pollution. Therefore, considering the spatial spillover effect of haze pollution from the perspective of urban agglomeration and longterm, strengthening the joint prevention and control and comprehensive treatment among cities, further promoting the rationalization and upgrading of industrial structure is conducive to reducing haze pollution.
\end{abstract}

Keywords: haze pollution; industrial structure; spatial direct effects; spatial spillover effects

\section{Introduction}

With the development of China's economy, environmental pollution is aggravating, especially haze pollution in China [1]. Haze pollution in China has increased the incidence of carcinogenesis, pathogenicity, and premature death [2]. Today's overcapacity and haze pollution is due to China's industrial structure, overemphasized heavy industry in the past 40 years [3]. The emergence of haze has a great relationship with people's production, especially the industrial structure is the source of haze [4]. As an important link between human economic activities and air quality, industrial structure is the key factor in resolving the contradiction between economic development and the environment [5].

Recently, the relationship between industrial structure and haze pollution has attracted the attention of academic circles. However, it has not been widely studied. There was a positive correlation between industrial structure and haze pollution, the increase of industrial proportion in Gross Domestic Product (GDP) would aggravate the degree of haze pollution [6]. According to Panel Vector Autoregression (PVAR) model, the industrial structure of 18 prefecture level cities in Henan Province aggravated haze pollution as a whole [7]. Wang [8] obtained the relationship between the industrial structure and haze pollution composite index in Anhui Province. The proportion of secondary and tertiary industries in GDP was usually used as a measure of industrial structure. The dynamic threshold panel model showed that the increase of the proportion of the secondary industry and the decrease of the proportion of the tertiary industry aggravated the environmental 
pollution [9]. Zhan [10] also found that the relationship between haze pollution and the proportion of tertiary industry output value in GDP is not significant. Furthermore, Zheng [5] analyzed and discussed the impact of industrial transformation on air pollution and the evolution of provincial heterogeneity. Zhu [11] found that improving the rationalization of industrial structure in Shanxi Province can promote the improvement of air quality. In addition, the upgrading of industrial structure was conducive to the improvement of air quality [12]. The above research on the relationship between industrial structure and haze pollution are mostly based on the Vector Autoregression (VAR) model, threshold regression model and so on.

Previous scholars used the traditional non-spatial regression model to study the impact of industrial structure on haze pollution. Considering the existence of the spatial correlation, traditional non-spatial regression methods may lead to errors [13]. Spatial regression models were widely used to identify spatial dependence by distinguishing the exogenous and endogenous interactions [14]. Wang [15] chose the generalized moment estimation method of the dynamic Spatial Lag Model (SLM) to study the influencing factors of haze pollution.Through SLM and Spatial Error Model (SEM), it was found that there are spatial dependence and positive spatial spillover effects in China's provincial environmental pollution. There was a significant positive correlation between industrial structure and environmental pollution [16]. Based on the Spatial Dubin Model (SDM), Wang [17] found that the industrial structure aggravated haze pollution, and Hui [18] also found that haze pollution in the Hebei Province has an obvious spatial spillover effect, and has certain continuity and "warning effect". Compared with SLM and SEM, SDM could estimate the influence of covariates on response variables based on the weighted average of neighborhood observations [19]. The spatial city model (SDM) of spatial effects was used to evaluate the spatial effects of haze pollution, and a coefficient of 0.416 was obtained, which indicates that the haze of adjacent cities affects each other and had significant spillover [20]. The previous studies, methods, and results are listed in Table 1.

Table 1. Summary of previous research methods and results.

\begin{tabular}{|c|c|c|c|}
\hline Previous Studies & Method Types & Methods & Results \\
\hline & \multirow{7}{*}{$\begin{array}{l}\text { Non-spatial } \\
\text { regression } \\
\text { models }\end{array}$} & Regression analysis of fixed effect model & The relationship between industry structure and haze pollution was positively correlated. \\
\hline [7] & & Panel vector autoregression & The industrial structure of 18 prefecture level cities in Henan Province has intensified the whole haze pollution. \\
\hline [8] & & Linear regression & An inverted U relationship between haze pollution and industrial structure in Anhui Province. \\
\hline$[9]$ & & Dynamic panel threshold model & The increase of the proportion of the secondary industry and the decrease of the proportion of the tertiary industry aggravate the environmental pollution. \\
\hline [10] & & $\begin{array}{l}\text { Generalized method of moments } \\
\text { Panel threshold model }\end{array}$ & $\begin{array}{l}\text { The relationship between haze pollution and the proportion of tertiary industry output value in GDP is not significant. } \\
\text { The impact mechanism of industrial structure on PM2 } 5 \text { is three levels }\end{array}$ \\
\hline [11] & & Panel threshold model & $\begin{array}{l}\text { Ihe mpact mechanism of industrial structure on PM.2.5 is three levesis. } \\
\text { Improving the rationalization of Shanxi industrial structure can promote the improvement of air quality. }\end{array}$ \\
\hline [12] & & Regression analysis; Correlation analysis & 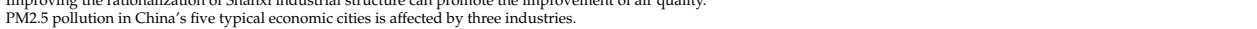 \\
\hline [15] & \multirow{5}{*}{$\begin{array}{l}\text { Spatial } \\
\text { regression } \\
\text { models }\end{array}$} & Spatial lag model & Haze pollution has spatial spillover effect and time lag effect. \\
\hline [16] & & Spatial lag model; Spatial error model & China's provincial environmental pollution has a positive spatial spillover effect, and the optimization and adjustment of industrial structure is helpful to reduce environmental pollution. \\
\hline [18] & & Spatial Dubin model & Haze pollution in Hebei Province has an obvious spatial spillover effect. \\
\hline [17] & & $\begin{array}{l}\text { Spatial Dubin model } \\
\text { Spatial Dubin model }\end{array}$ & Industrial structure will aggravate haze pollution \\
\hline & & Spatial Dubin model & \\
\hline
\end{tabular}

PM2.5 is usually used as an important indicator of haze pollution [21]. Compared with PM10, PM2.5 has smaller particle size, larger specific surface area, stronger activity, more easily attached toxic and harmful substances (such as heavy metals, microorganisms), longer residence time in the atmosphere, long transportation distance, and greater harm to human health [22]. Specifically, the areas of high-frequency haze pollution in China are mainly distributed in the economic concentration regions, such as the Yangtze River Delta [23]. As shown in Figure 1, 2013 was the most serious year of haze pollution in the Yangtze River Delta region. Only five cities had low PM2.5 concentration, and most cities had serious haze pollution and regional concentration. Therefore, this study selects the average annual PM2.5 data of 41 cities in the Yangtze River Delta from 2002 to 2016, and uses a spatial Durbin model (SDM) to analyze the impact of industrial structure on haze pollution.

In this paper, we analyzed the impact of industrial structure adjustment on haze pollution from the regional perspective firstly. Secondly, based on the Yangtze River Delta haze area, we analyzed the spillover effect of haze pollution between cities and the spatial spillover effect of industrial structure on haze pollution from the static and dynamic perspectives, and reexamined the impact of industrial structure on haze pollution. 
In addition, on the basis of the research results of other scholars, this paper selected the rationalization of industrial structure and the upgrading of industrial structure as the indicators of industrial structure, which can more comprehensively analyze the impact of industrial structure on haze pollution. Finally, based on the estimation of model parameters, the model effect is estimated, and the spatial direct effect and spatial spillover effect of industrial structure on haze pollution are further analyzed.

This paper is organized as follows: the Introduction is presented in Section 1; Section 2 presents the research methods, variable description and data sources; Section 3 includes the empirical analysis and robustness test; and Section 4 presents the conclusions, policy implications, and research prospects, followed by references.

口21.819069 - 32.550432

$\square 32.550433-43.281795$

$\square 43.281796-54.013157$

$54.013158-64.744520$

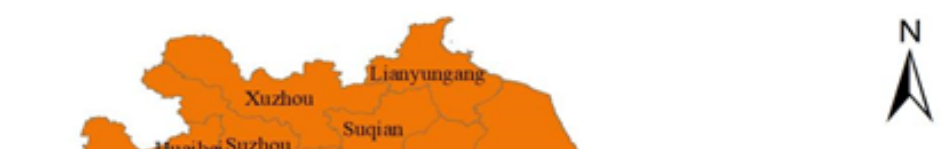

Figure 1. The spatial-distribution of haze pollution in Yangtze River Delta in 2013.

\section{Methodology and Variables}

\subsection{Spatial Correlation Test}

Global Moran's I was used to describe the spatial characteristics of PM2.5 concentration in the whole region. The range of Moran's $I$ index $I$ is $[-1,1]$. The larger the absolute value of $I$, the higher the degree of spatial correlation. $I>0$ indicates that there is spatial positive correlation for PM2.5 concentration in each region, $I<0$ indicates that there is a spatial negative correlation for PM2.5 concentration in each region, and $I=0$ indicates that there is no spatial correlation for PM2.5 concentration in each region. Moran's I is calculated as follows:

$$
\begin{gathered}
I=\left[\sum_{i=1}^{n} \sum_{j=1}^{n} W_{i j}\left(x_{i}-\bar{x}\right)\left(x_{j}-\bar{x}\right)\right] /\left[s^{2} \sum_{i=1}^{n} \sum_{j=1}^{n} W_{i j}\right] \\
s^{2}=(1 / n) \sum_{i=1}^{n}\left(x_{i}-\bar{x}\right)^{2}, \bar{x}=(1 / n) \sum_{i=1}^{n} x_{i}
\end{gathered}
$$

where $x_{i}$ is the annual average PM2.5 concentration of the city $i, n$ is the number of cities, $W_{i j}$ is a weighting matrix representing the spatial weight of cities $i$ and $j$.

Although the global Moran's I can test the overall characteristics and trends of spatial correlation of air pollution, there are still some defects. If there is a positive correlation in some cities and negative correlation in other cities, the positive and negative effects will be offset, and the conclusion is that there is no spatial correlation in the air pollution of urban agglomeration. Therefore, it is necessary to further test whether there is local spatial 
concentration of air pollution through Moran's I scatterplot. There are four quadrants in Moran's I scatterplot, the points in the first quadrant $(\mathrm{HH})$ and the third quadrant (LL) represent positive spatial correlation, and the fourth (HL) and second (LH) quadrants represent negative spatial correlation.

\subsection{Model Setting}

Based on Elhorst [14], this paper established the following spatial Dubin model:

$$
\begin{gathered}
Y_{i t}=\rho W Y_{i t}+\beta X_{i t}+\theta W X_{i t}+\mu_{i}+\lambda_{t}+\varepsilon_{i t} \\
Y_{i t}=\rho W Y_{i t}+\tau Y_{i, t-1}+\beta X_{i t}+\theta W X_{i t}+\mu_{i}+\lambda_{t}+\varepsilon_{i t} \\
Y_{i t}=\ln P M_{i t} \\
X_{i t}=\left[R S_{i t}, U S_{i t}, \ln G D P_{i t}, \ln G D P 2_{i t}, \ln P D I_{i t}, \ln S I Z E_{i t}, \ln P U_{i t}\right]
\end{gathered}
$$

Equation (3) is the form of the static spatial Durbin model. On the basis of Equation (3), the time lag term is introduced to construct dynamic spatial Durbin model Equation (4), where $Y_{i t}$ is the dependent variable in city $i$ at time $t, \rho$ is the spatial lag coefficient of the dependent variable, $\tau$ is the time lag coefficient of the dependent variable, $X_{i t}$ is the independent variable in city at time $t, \beta$ is the direct coefficient of the independent variable, and $\theta$ is the spatial lag coefficient of the independent variable, $W$ is the spatial weight matrix, $\mu_{i}$ is the spatial effect, $\lambda_{t}$ is the time fixed effect, and $\varepsilon_{i t}$ is the random error vector.When $\tau=0$, the dynamic spatial Durbin model degenerates to the static spatial Durbin model. In order to further measure the spatial effect of haze pollution, the dependent variable term on the right side of the equal sign is moved to the left side of the equal sign, and Equation (4) is rewritten as follows:

$$
\begin{gathered}
(I-\rho W) Y_{i t}=\tau Y_{i, t-1}+\beta X_{i t}+\theta W X_{i t}+\mu_{i}+\lambda_{t}+\varepsilon_{i t} \\
Y_{i t}=(I-\rho W)^{-1} \tau Y_{i, t-1}+(I-\rho W)^{-1}\left(\beta X_{i t}+\theta W X_{i t}\right)+(I-\rho W)^{-1}\left(\mu_{i}+\lambda_{t}+\varepsilon_{i t}\right)
\end{gathered}
$$

The matrixes of the partial derivative of the expected value of $Y_{i t}$ relative to the kth independent variable of $X_{i t}$ with unit 1 to 41 at specific points in the short-term scale and long-term scale can be regarded as the following equations:

$$
\begin{gathered}
{\left[\frac{\partial E\left(Y_{1 t}\right)}{\partial X_{1 k}} \cdots \frac{\partial E\left(Y_{41 t}\right)}{\partial X_{41 k}}\right]=(I-\rho W)^{-1} *\left[\begin{array}{cccc}
\theta_{k} & W_{12} \theta_{k} & \cdots & W_{1,41} \theta_{k} \\
W_{21} \theta_{k} & \theta_{k} & \cdots & W_{2,41} \theta_{k} \\
\vdots & \vdots & \ddots & \vdots \\
W_{41,1} \theta_{k} & W_{41,2} \theta_{k} & \cdots & \theta_{k}
\end{array}\right]} \\
{\left[\frac{\partial E\left(Y_{1 t}\right)}{\partial X_{1 k}} \cdots \frac{\partial E\left(Y_{41 t}\right)}{\partial X_{41 k}}\right]=(I-\rho W-\tau I)^{-1} \text { ast }\left[\begin{array}{cccc}
\theta_{k} & W_{12} \theta_{k} & \cdots & W_{1,41} \theta_{k} \\
W_{21} \theta_{k} & \theta_{k} & \cdots & W_{2,41} \theta_{k} \\
\vdots & \vdots & \ddots & \vdots \\
W_{41,1} \theta_{k} & W_{41,2} \theta_{k} & \cdots & \theta_{k}
\end{array}\right]}
\end{gathered}
$$

In the partial derivative matrix (9), the mean value of diagonal elements represents the short-term spatial direct effect, and the mean value of the sum of rows or columns of non diagonal elements represents the short-term spatial spillover effect.

In the partial derivative matrix (10), the mean value of diagonal elements represents the long-term spatial direct effect, and the mean value of the row sum or column sum of non diagonal elements represents the long-term spatial spillover effect.

\subsection{Spatial Weight Matrix}

The spatial weight matrix reflects the geographical position of each region. Most spatial econometric models at home and abroad use the adjacency matrix, inverse distance matrix, and economic weight matrix, which only consider the differences of geographical 
or economic factors. In order to comprehensively consider the spatial geographical distance characteristics and economic related attributes, the nested matrix and the spatial weight matrix of economic geographical distance are selected as follows:

$$
\begin{gathered}
W_{g}=W_{i j}=\left\{\begin{array}{cc}
0 & i=j \\
\frac{1}{d_{i j}{ }^{2}} & i \neq j
\end{array}\right. \\
W_{e}=M_{i j}=\left\{\begin{array}{cc}
0 & i=j \\
\frac{1}{\left|\overline{X_{i}}-\overline{X_{j}}\right|} \quad i \neq j
\end{array}\right. \\
W_{\alpha}=W_{g} * \operatorname{diag}\left(\frac{\bar{X}_{1}}{\bar{X}}, \frac{\bar{X}_{2}}{\bar{X}}, \ldots, \frac{\bar{X}_{N}}{\bar{X}}\right), W_{\xi}=W_{g} * W_{e} \\
\bar{X}_{i}=\frac{1}{T} \sum_{t=1}^{T} x_{i t}, \bar{X}=\frac{1}{N * T} \sum_{i=1}^{N} \sum_{t=1}^{T} x_{i t}
\end{gathered}
$$

where $W_{g}$ is the inverse distance weight matrix, $W_{e}$ is the economic distance matrix, $W_{\alpha}$ is the nested matrix, $W_{\mathcal{\zeta}}$ is the economic geographical distance spatial weight matrix, and $d_{i j}$ is the geographical distance calculated according to the longitude and latitude of the cities, $x_{i t}$ is the GDP per capita of city $i$ in year $t, \bar{X}_{i}$ is the GDP per capita of city $i$ in $T$ years, $\bar{X}$ is the per capita GDP of all sample cities in $T$ years.

\subsection{Data Sources}

China's atmospheric environment monitoring system only included PM2.5 concentration into the monitoring index system in 2012, and only a few key cities were involved. Compared with ground monitoring data, satellite monitoring data can provide PM2.5 concentration with larger scope, wider coverage and higher spatial resolution. The PM2.5 data used in this study is from the center for socio economic data and applications at Columbia University (SEDAC) [24]. Through the transformation of satellite remote sensing technology and the geochemical transmission model, as well as the prediction and adjustment of geographically weighted regression model, the global PM2.5 grid data are formed. Furthermore, taking the vector boundaries of the administrative divisions of the Yangtze River Delta region as the mask, the grid data are counted and extracted using spatial analyst tool in ArcGIS 10.2 software, and the PM2.5 concentration data of 41 cities in Yangtze River Delta from 2002 to 2016 is obtained. Other data of the Yangtze River Delta from 2002 to 2016 are from the Anhui statistical yearbook, Jiangsu statistical yearbook, Zhejiang statistical yearbook, and Shanghai Statistical Yearbook. The descriptive statistics

\begin{tabular}{|c|c|c|c|c|c|}
\hline Variable Type & Variable Name & Variable Indicator & Shorthand & Mean & Std. Dev. \\
\hline Explained variable & Haze pollution & PM2.5 annual average concentration $\left(\mathrm{ug} / \mathrm{m}^{3}\right)$ & $\ln P M$ & 3.833186 & 0.3026283 \\
\hline & Industrial structure & $\begin{array}{l}\text { Rationalization of industrial structure } \\
\text { Upgrading of industrial structure }\end{array}$ & $\begin{array}{l}\text { RS } \\
\text { US }\end{array}$ & $\begin{array}{l}23.7826 \\
0.832070\end{array}$ & $\begin{array}{l}87.38896 \\
0.2545545\end{array}$ \\
\hline \multirow[b]{2}{*}{ Control variables } & Economic development & $\begin{array}{l}\text { Per capita GDP (yuan) } \\
\text { The second term of per capita GDP (yuan) }\end{array}$ & $\begin{array}{l}\operatorname{lnGDP} \\
\operatorname{lnGDP2}\end{array}$ & $\begin{array}{l}0.8320 / 01 \\
10.2616 \\
106.0454\end{array}$ & $\begin{array}{l}0.2543545 \\
0.8637546 \\
17.43869\end{array}$ \\
\hline & $\begin{array}{l}\text { Open level } \\
\text { Scale of industrial enterprises } \\
\text { Population density }\end{array}$ & $\begin{array}{l}\text { Foreign direct investment (ten thousand dollars) } \\
\text { Number of enterprises meeting certain scale requirements } \\
\text { Population per unit area of land (person } / \mathrm{km}^{2} \text { ) }\end{array}$ & $\begin{array}{l}\ln F D I \\
\ln S I Z E \\
\ln P U\end{array}$ & $\begin{array}{l}10.33189 \\
7.290136 \\
6.363183\end{array}$ & $\begin{array}{l}1.736633 \\
1.17125 \\
0.5582924\end{array}$ \\
\hline
\end{tabular}
of the variables are shown in Table 2. The variable average data of per cities in the Yangtze River Delta are listed in Table 3.

Table 2. Variable description. 


\subsection{Index Selection}

2.5.1. Explained Variable

Haze pollution( $(\mathrm{nPM})$ : Research shows that the main particulate matter causing haze pollution is PM2.5 [21]. Therefore, PM2.5 is used as the explained variable to measure the haze pollution.

Table 3. Mean value of each city variable.

\begin{tabular}{|c|c|c|c|c|c|c|c|c|}
\hline City & $\ln P M$ & RS & US & $\operatorname{lnGDP}$ & lnGDP2 & $\operatorname{lnFDI}$ & $\operatorname{lnSIZE}$ & $\ln P U$ \\
\hline Anqing & 3.7700 & 5.1282 & 0.7336 & 9.5542 & 91.7117 & 9.2619 & 6.9135 & 5.9885 \\
\hline Bengbu & 4.0162 & 4.7769 & 0.8549 & 9.7128 & 94.7579 & 10.0866 & 6.1461 & 6.4041 \\
\hline Bozhou & 4.0568 & 8.2720 & 1.1570 & 9.0816 & 82.8415 & 8.9537 & 5.8054 & 6.5535 \\
\hline Changzhou & 4.0699 & 22.4795 & 0.7585 & 10.9792 & 120.8114 & 11.8807 & 8.3157 & 6.7266 \\
\hline Chizhou & 3.6374 & 5.3553 & 0.9012 & 9.6482 & 93.6631 & 8.9501 & 5.6644 & 5.2568 \\
\hline Chuzhou & 4.0181 & 6.7548 & 0.6823 & 9.6226 & 92.9290 & 9.4798 & 6.6843 & 5.7958 \\
\hline Fuyang & 4.0187 & 13.9474 & 1.0196 & 8.8770 & 79.2527 & 8.2815 & 6.3172 & 6.9194 \\
\hline Hangzhou & 3.5940 & 22.1826 & 1.0607 & 11.0328 & 121.9363 & 12.6291 & 8.8117 & 6.0206 \\
\hline Hefei & 4.0014 & 6.4460 & 0.8274 & 10.4171 & 108.9888 & 11.1493 & 7.1684 & 6.4683 \\
\hline Huzhou & 3.8638 & 41.6321 & 0.7155 & 10.5363 & 111.2869 & 11.2786 & 7.7483 & 6.1022 \\
\hline Huaian & 4.0058 & 8.6792 & 0.8233 & 9.9992 & 100.5083 & 10.3285 & 7.3279 & 6.2761 \\
\hline Huaibei & 4.0584 & 6.1430 & 0.5806 & 9.7568 & 95.5747 & 9.1950 & 5.8471 & 6.6605 \\
\hline Huainan & 4.0000 & 10.2288 & 0.6700 & 9.8404 & 97.1124 & 9.2089 & 5.7274 & 6.8291 \\
\hline Huangshan & 3.4528 & 8.1822 & 1.2131 & 9.8432 & 97.2488 & 8.9353 & 5.8422 & 5.0159 \\
\hline Jiaxing & 3.9831 & 54.5819 & 0.6645 & 10.7353 & 115.4242 & 11.8991 & 8.4146 & 6.7634 \\
\hline Jinhua & 3.4665 & 8.5982 & 0.8736 & 10.5407 & 111.3854 & 10.3804 & 8.1834 & 6.0504 \\
\hline Lishui & 3.1084 & 4.2123 & 0.9040 & 10.1402 & 103.1881 & 8.4393 & 6.8617 & 5.0012 \\
\hline Lianyungang & 3.9678 & 9.7658 & 0.8345 & 9.9045 & 98.5809 & 10.2947 & 7.0195 & 6.4764 \\
\hline Luan & 3.8459 & 4.8052 & 0.9004 & 9.1355 & 83.9171 & 8.9771 & 6.4631 & 5.9557 \\
\hline Maanshan & 4.0267 & 6.0734 & 0.5103 & 10.6045 & 112.7148 & 10.4615 & 6.2798 & 6.5060 \\
\hline Nanjing & 4.0468 & 16.8192 & 1.1255 & & 121.3710 & 12.4296 & 7.8200 & 6.8633 \\
\hline Nantong & 4.0131 & 14.8040 & 0.7238 & 10.5015 & 110.7457 & 11.0212 & 8.3911 & 6.8090 \\
\hline Ningbo & 3.4869 & 306.0934 & 0.7724 & 10.9993 & 121.1781 & 12.4683 & 8.9658 & 6.3784 \\
\hline Quzhou & 3.4135 & 4.0869 & 0.8190 & 10.0900 & 102.1869 & 8.3636 & 6.7687 & 5.6455 \\
\hline Shanghai & 3.9525 & 35.9339 & 1.4590 & 11.1314 & 124.0371 & 13.8528 & 9.3955 & 8.1229 \\
\hline Shaoxing & 3.5789 & 19.3106 & 0.6880 & 10.8069 & 117.0363 & 11.3077 & 8.2781 & 6.2736 \\
\hline Suzhou & 4.0816 & 35.5714 & 0.7139 & 11.3853 & 129.7791 & 12.7183 & 9.0465 & 6.6389 \\
\hline Suqian & 3.2433 & 13.4251 & 0.8537 & & 109.3402 & 10.0959 & 8.3007 & 6.4181 \\
\hline Suzhou & 4.0969 & 9.4963 & 0.7087 & 10.3999 & 108.6636 & 10.4425 & 7.7557 & 6.7642 \\
\hline Taizhou & 3.8665 & 4.0216 & 0.4725 & 10.6788 & 114.4385 & 8.9778 & 5.3656 & 6.4581 \\
\hline Taihzhou & 3.1395 & 14.4825 & 0.9192 & 10.3850 & 108.0573 & 10.1691 & 8.5686 & 6.4877 \\
\hline Tongling & 4.0871 & 30.2167 & 0.7945 & 11.3462 & 128.8997 & 12.1771 & 8.5413 & 6.9122 \\
\hline Wenzhou & 3.8994 & 4.0065 & 0.5580 & 10.4085 & 108.7155 & 10.7613 & 6.9925 & 6.5036 \\
\hline Wuxi & 4.0081 & 13.7081 & 0.7615 & 9.6919 & 94.5560 & 8.4426 & 7.2200 & 6.4492 \\
\hline Wuhu & 4.0521 & 9.9851 & 1.0687 & 9.2046 & 85.1331 & 9.0715 & 6.2650 & 6.4520 \\
\hline Xuzhou & 4.0698 & 5.9016 & 0.8142 & 10.1708 & 103.9113 & 10.6744 & 7.5981 & 6.7331 \\
\hline Xuancheng & 3.6874 & 5.0992 & 0.8115 & 9.7760 & 95.9344 & 9.5110 & 6.6633 & 5.4145 \\
\hline Yancheng & 3.9661 & 12.3192 & 0.7931 & 10.1049 & 102.5694 & 9.9702 & 7.8490 & 6.1886 \\
\hline Yangzhou & 4.0698 & 27.4899 & 0.7258 & 10.5605 & 111.9754 & 11.2172 & 7.8098 & 6.5354 \\
\hline Zhenjiang & 4.0900 & 14.3255 & 0.7229 & 10.9103 & 119.3356 & 10.9785 & 7.7095 & 6.5642 \\
\hline Zhoushan & 3.3498 & 119.7451 & 1.1240 & 10.7612 & 116.1625 & 8.8861 & 6.0493 & 6.5074 \\
\hline
\end{tabular}

\subsubsection{Explanatory Variables}

Rationalization of industrial structure (RS): RS is used to measure the coupling degree of factor input structure and output structure. The larger the RS value is, the better the coupling degree is and the more reasonable the industrial structure is; otherwise, the 
coupling degree is poor and the industrial structure is unreasonable. RS is calculated according to the following equation:

$$
\left.R S=\frac{1}{\sum_{i=1}^{3}\left(\frac{Y_{i}}{Y}\right) \ln \left(\frac{Y_{i}}{Y} / \frac{L_{i}}{L}\right.}\right)
$$

where $Y$ is the output value, $L$ is the employment, $Y_{i}$ is the $i$ industry Value $(i=1,2,3)$, and $L_{i}$ is the number of employment in the $i$ industry.

Upgrading of industrial structure (US): US is calculated by the ratio of the output value of the tertiary industry and the secondary industry. With the increase of US value, the industrial structure gradually develops to the direction of low pollution service.

\subsubsection{Control Variables}

Economic development (lnGDP, InGDP2): Urban per capita GDP is used as a measure of economic development and compared with the total GDP of each region used in other literature. The GDP per capita represents the level of local economic development more accurately while considering the population factor $[3,25]$. The LnGDP2 is a square of LnGDP. The addition of the square of per capita real GDP in the econometric model is to test the Environmental Kuznets Curve hypothesis [26].

Open level (lnFDI): The foreign direct investment of the city is selected as the open level. There are two hypotheses about the impact of FDI on environmental pollution, but scholars have not reached a consensus. The pollution haven hypothesis is that the entry of foreign capital effectively increases the productivity of domestic enterprises through spillover effects [27] and promotes the efficiency of environmental resources usage, and thereby effectively reduces environmental pollution. Pollution haven mainly refers to the fact that developed countries can transfer their high pollution industries to developing countries, thus worsening the environmental quality of the host countries.

Scale of industrial enterprises (lnSIZE): The number of industrial enterprises above scale is selected to measure the scale of industrial enterprises. Industry is the main source of air pollution. The more large-scale industrial enterprises are, the more likely it is to aggravate urban air pollution.

Population density (lnPU): Population per unit area of land represents the clustering degree of urban population. The higher the population density, the more frequent social and economic exchanges, such as public transportation and freight transportation of urban population, and the higher the likelihood of urban air pollution [28].

\section{Empirical Analysis}

\subsection{Unit Root Test}

In order to avoid the false regression of empirical results, the LLC and ADF unit root tests are conducted on the panel data. The results in Table 4 show that all variable data pass the unit root test and are stable.

Table 4. Unit root test.

\begin{tabular}{lll}
\hline Variables & LLC Test & ADF Test \\
\hline $\ln$ PM2.5 & $-18.2351^{* * *}$ & $114.9152^{* * *}$ \\
RS & $-8.0235^{* * *}$ & $356.9565^{* * *}$ \\
US & $-6.7316^{* * *}$ & $108.1569^{* *}$ \\
$\operatorname{lnGDP}$ & $-4.4381^{* * *}$ & $182.6425^{* * *}$ \\
$\operatorname{lnGDP2}$ & $-4.1316^{* * *}$ & $134.0043^{* * *}$ \\
$\operatorname{lnFDI}$ & $-3.3055^{* * *}$ & $158.0533^{* * *}$ \\
$\operatorname{lnSIZE}$ & $-12.5218^{* * *}$ & $122.8403^{* * *}$ \\
$\operatorname{lnPU}$ & $-5.3043^{* * *}$ & $112.3907^{* *}$ \\
\hline Note: & &
\end{tabular}




\subsection{Spatial Correlation Test of Haze Pollution}

The spatial spillover effect of haze pollution is judged by global and local correlation tests. The global Moran's I test results of PM2.5 concentration from 2002 to 2016 are shown in Table 5, all Moran's I values are greater than 0.2 , and for the hypothesis test of Moran's I, the $p$-values are smaller than 0.01 , which shows a significant spatial correlation of haze pollution in Yangtze River Delta urban agglomeration. In addition, in the 2016 local Moran's I scatter diagram, as shown in Figure 2, we find that most cities are concentrated in the first and third quadrants, which is consistent with the global Moran's I test results, further supporting the spatial spillover effect of haze pollution in the Yangtze River Delta. Therefore, there is a spatial spillover effect of haze pollution in Yangtze River Delta urban agglomeration. Regional governments should strengthen the joint prevention and control of haze pollution, and cities with high PM2.5 value should become the key areas of regional joint prevention and control of haze pollution.

Table 5. Moran's I value with spatial correlation estimation.

\begin{tabular}{ll}
\hline Variables & Moran's I Value \\
\hline PM2.5_2002 & $0.228^{* * *}$ \\
PM2.5_2003 & $0.221^{* * *}$ \\
PM2.5_2004 & $0.234^{* * *}$ \\
PM2.5_2005 & $0.230^{* * *}$ \\
PM2.5_2006 & $0.244^{* * *}$ \\
PM2.5_2007 & $0.225^{* * *}$ \\
PM2.5_2008 & $0.227^{* * *}$ \\
PM2.5_2009 & $0.243^{* * *}$ \\
PM2.5_2010 & $0.240^{* * *}$ \\
PM2.5_2011 & $0.248^{* * *}$ \\
PM2.5_2012 & $0.225^{* * *}$ \\
PM2.5_2013 & $0.236^{* * *}$ \\
PM2.5_2014 & $0.253^{* * *}$ \\
PM2.5_2015 & $0.252^{* * *}$ \\
PM2.5_2016 & $0.247^{* * *}$ \\
\hline
\end{tabular}

Note: ${ }^{* * *} p<0.01$.

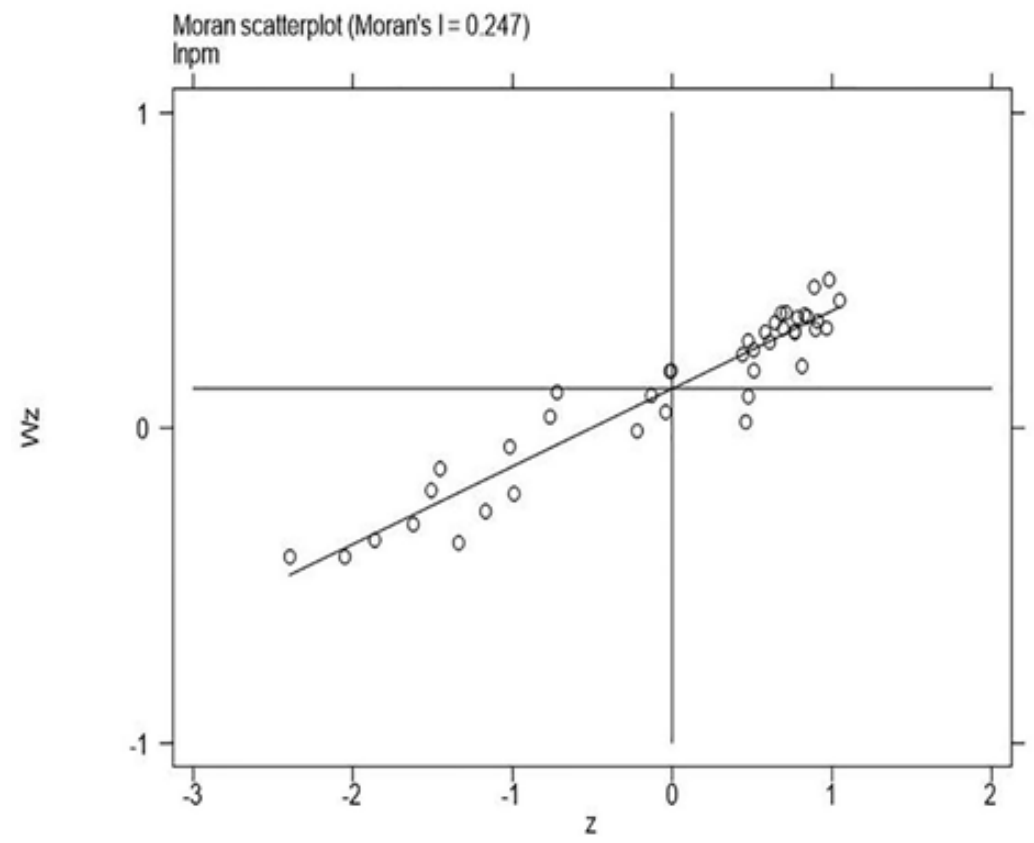

Figure 2. Moran's I scatterplot of PM2.5 concentration in 2016. 


\subsection{Spatial Econometric Model Selection Test}

On the basis of Moran's I test, this paper further tests whether the spatial econometric model can be used in empirical research. The test results are shown in Table 6. The LM Test in Table 6 shows that LM lag, robust LM lag, LM error, and robust LM error of the two matrices are significant at a $1 \%$ level, so it is reasonable to choose the spatial Durbin model. Secondly, the Wald test and LR test show that, at the level of $1 \%$, the Wald value and LR value hypothesis of SAR and SEM models are significantly rejected. Therefore, SDM cannot be degraded to the SAR or SEM model. Finally, the Hausman test shows that the fixed effect is better than the random effect. To sum up, SDM is a more suitable spatial spillover effect model, and we choose SDM with the fixed effect.

Table 6. Spatial econometric model selection test.

\begin{tabular}{ll}
\hline Tests & Statistical Values \\
\hline LM_spatial_error & $780.303^{* * * *}$ \\
robust LM_spatial_error & $49.867^{* * *}$ \\
LM_spatial_lag & $828.391^{* * *}$ \\
robust LM_spatial_lag & $97.955^{* * *}$ \\
Wald_spatial_lag & $406.70^{* * *}$ \\
Wald_spatial_error & $658.25^{* * *}$ \\
LR_spatial_lag & $459.20^{* * *}$ \\
LR_spatial_error & $557.13^{* * *}$ \\
Hausman test & $55.72^{* * *}$ \\
\hline Note: &
\end{tabular}

\subsection{SDM Parameter Estimation}

The parameters of static and dynamic Durbin models are estimated, and the results are shown in Table 7 . The results show that the spatial correlation coefficients of the two models are both positive at the significance level of $1 \%$, which indicates that the haze pollution of adjacent cities will also aggravate the local haze pollution, and there is a spatial spillover effect of haze. In these two models, the coefficient of per capita GDP and the quadratic term pass the test at the significance level of $1 \%$. The GDP coefficient is negative and the quadratic coefficient is positive. This shows that there is no "inverted U" EKC curve between haze pollution and per capita GDP, but there is a positive " $U$ " curve, that is, with economic growth, environmental pollution first decreases and then increases. The coefficient of the number of Industrial Enterprises above the designated size is negative, which has an inhibitory effect on haze pollution, but not a significant one. The coefficients of FDI and population density are positive, but not significant in the dynamic model, which can promote the haze pollution. In the dynamic model, the first-order lag coefficient of PM2.5 concentration is positive at the significance level of $1 \%$, which indicates that urban PM2.5 has a significant dynamic effect.

In addition, we find that, in the static model, the rationalization and upgrading of industrial structure are all at a $1 \%$ significant level, which can inhibit the haze pollution. It shows that, with the optimization of industrial structure, the haze pollution will be reduced, and the factors in the rationalization process will flow into the modern industry and service industry with higher production return rate, which can promote the development of emerging industries, reduce the haze emissions and accelerate the production speed. The growth rate tends to equilibrium. However, in the dynamic model, the rationalization and upgrading of industrial structure have no inhibitory effect on haze pollution, which is completely opposite to the static model. It may be that the dynamic effect of PM2.5 is added into the dynamic model, which leads to the difference of parameter estimation results between the two models. Finally, we find that the spatial spillover effects of variables in the two models are the opposite. This interferes with our research on the spatial spillover effect of industrial structure optimization on haze pollution. 


\subsection{SDM Effect Estimation}

In order to more accurately analyze the spatial spillover effect of rationalization and upgrading of industrial structure on haze pollution, we will estimate the direct effect and spatial spillover effect of SDM model from static and dynamic perspectives. Lesage and Pace [19] believe that, due to the existence of the feedback effect, it may be wrong to use point estimation results to directly explain the spatial spillover effect, and proposed an effect measurement method based on the partial differential.

Table 7. SDM parameter estimation.

\begin{tabular}{|c|c|c|}
\hline Variables & Static & Dynamic \\
\hline RS & $-0.0002^{* * *}$ & 0.0000206 \\
\hline US & $-0.1459 * * *$ & $0.0374^{* *}$ \\
\hline $\operatorname{lnGDP}$ & $-0.4801^{* * *}$ & $-0.2947^{* * *}$ \\
\hline $\operatorname{lnGDP2}$ & $0.0225^{* * *}$ & $0.0148^{* * *}$ \\
\hline $\operatorname{lnSIZE}$ & -0.009 & -0.0013 \\
\hline $\operatorname{lnFDI}$ & $0.0305^{* * *}$ & 0.002 \\
\hline $\ln P U$ & $0.1258^{* * *}$ & 0.0131 \\
\hline $\ln P M(-1)$ & & $0.7601^{* * *}$ \\
\hline WRS & $-0.0012^{* * *}$ & 0.0002 \\
\hline WUS & $-1.1276^{* * *}$ & $1.4844^{* * *}$ \\
\hline WlnGDP & $-5.0719 * * *$ & $7.2598 * * *$ \\
\hline$W \ln G D P 2$ & $0.2193 * * *$ & $-0.3407^{* * *}$ \\
\hline WlnSIZE & $-0.5456^{* * *}$ & 0.0795 * \\
\hline WlnFDI & $0.4911^{* * *}$ & $-0.1206^{* * *}$ \\
\hline WlnPU & $1.3076^{* * *}$ & $-0.5152^{* * *}$ \\
\hline Spatial rho & $0.6880^{* * *}$ & $1.9393^{* * *}$ \\
\hline sigma2_e & $0.0122^{* * *}$ & $0.0040^{* * *}$ \\
\hline
\end{tabular}

\subsubsection{Spatial Direct Effect}

The spatial direct effects of SDM include the long-term direct effects of the static model and the long-term and short-term direct effects of the dynamic model, the results are shown in Table 8. In the static and dynamic models, the long-term and short-term direct effects of GDP per capita, quadratic term of GDP per capita, number of Industrial Enterprises above Designated Size, FDI, and population density on haze pollution are basically consistent with the parameters in SDM.

Table 8. Spatial direct effect.

\begin{tabular}{llll}
\hline Variables & Static Long-Term & Dynamic Long-Term & Dynamic Short-Term \\
\hline RS & $-0.0003^{* * *}$ & $7.95 \times 10^{-6}$ & 0.0000162 \\
US & $-0.2278^{* * *}$ & -0.2355 & 0.0169 \\
$\operatorname{lnGDP}$ & $-0.8293^{* * *}$ & $-2.3112^{* * *}$ & $-0.3871^{* * *}$ \\
$\operatorname{lnGDP2}$ & $0.0376^{* * *}$ & $0.1107^{* * *}$ & $0.0191^{* * *}$ \\
$\operatorname{lnSIZE}$ & $-0.0454^{* * *}$ & -0.0184 & -0.0019 \\
$\operatorname{lnFDI}$ & $0.0648^{* * *}$ & 0.0306 & 0.0034 \\
$\ln \mathrm{PU}$ & $0.2187^{* * *}$ & $0.1439^{* * *}$ & $0.0195^{* *}$ \\
\hline
\end{tabular}

In the static model, the rationalization and upgrading of industrial structure have a long-term negative spatial direct impact on haze pollution at the $1 \%$ significant level. In the long-term, the rationalization and upgrading of industrial structure are conducive to haze emission reduction. The upgrading of industrial structure has reduced the proportion of heavy industry, eliminated high pollution enterprises, developed the industry into a 
low pollution service industry, and effectively reduced PM2.5 emissions. The reasonable development of industrial structure can realize the reasonable allocation of production factors, make the coordinated development of various industries, and effectively reduce the phenomenon of overcapacity, so as to reduce haze pollution. In the dynamic model, industrial structure upgrading also has a long-term negative spatial direct effect on haze pollution, and industrial structure upgrading can inhibit haze pollution. However, the rationalization of industrial structure has no long-term negative space direct impact on haze pollution, and has no inhibitory effect on haze pollution. It may be that the industrial structure of the Yangtze River Delta region is unreasonable, the allocation of production factors is unreasonable, the development of industrial structure rationalization is not paid attention to while the economic growth, and the rationalization of industrial structure does not give full play to the role of economic growth in restraining haze pollution. In the short run, the rationalization and upgrading of industrial structure have no direct negative impact on haze pollution, and has no inhibitory effect on haze pollution. This may be due to the dynamic effect of PM2.5 and the time needed to optimize and upgrade the industrial structure. In a short time, the rationalization and upgrading of industrial structure can not achieve haze emission reduction. The rationalization coefficient of industrial structure of the two models is far less than the rationalization coefficient of industrial structure upgrading, which indicates that the advantages of industrial structure upgrading on enterprises and haze control in the Yangtze River Delta region have been initially revealed, and the rationalization of industrial structure is not enough. We should further adjust the industrial structure, realize the rational allocation of production factors, and give full play to the role of restraining haze pollution through the rational utilization of industrial structure.

In addition, we find that the long-term spatial direct effect is greater than the shortterm spatial direct effect in the dynamic model, which is consistent with the cumulative effect in economy. When the regional haze pollution is significantly reduced, people's expectation of haze pollution will increase and put forward higher requirements, which will lead to the government to take more large-scale measures to control the above factors in the next few years. Therefore, the local government should formulate haze control policies with a long-term perspective, select model cities for haze control, form a positive learning and imitation atmosphere, and reduce urban haze pollution.

\subsubsection{Spatial Spillover Effects}

The spatial spillover effects of SDM include the long-term spillover effects of static model and the long-term and short-term spillover effects of dynamic model. The results are shown in Table 9. In the two models, the per capita GDP of surrounding cities has long-term and short-term spatial spillover effects on local haze pollution at the significant level of $1 \%$, which is a positive " $\mathrm{U}$ " curve because the economic growth of surrounding cities also drives local economic growth through regional economic ties; The number of Industrial Enterprises above designated size has long-term and short-term negative spatial spillover effects on haze pollution, that is, the number of Industrial Enterprises above Designated Size in adjacent cities has an inhibitory effect on local haze pollution. Due to the development of science and technology, enterprises in adjacent cities are more efficient and green in dealing with pollutants, and this technology and enterprise mode are more likely to be "imitated" and "learned" by local enterprises. FDI and population density have long-term and short-term positive spatial spillover effects on haze pollution at $1 \%$ and $10 \%$ significant levels, that is, FDI and population density of adjacent cities can promote local haze pollution because local governments are willing to imitate surrounding cities, reduce regional environmental regulations and standards, and attract foreign investment. Developed countries will transfer high polluting enterprises to local areas, which will aggravate the local haze pollution. Meanwhile, affected by the economic ties between regions, the local economic level will also be improved, and the population will choose to gather in the local areas, which will lead to more frequent traffic, production, and living 
activities in local cities, bring pressure to the urban environment, and also more likely aggravate the local haze pollution.

In the static model, the rationalization and upgrading of industrial structure has a long-term negative spatial spillover effect on haze pollution at a $1 \%$ significant level. In the long-term, the rationalization and upgrading of industrial structure of adjacent cities can inhibit local haze pollution. Through the exchange, cooperation, and learning between local enterprises and enterprises in neighboring cities, the technology of local enterprises has been innovated and developed, a new mode of production and service integration has been formed, a more reasonable and advanced industrial structure has been formed, and the local haze pollution has been reduced. In the dynamic model, the rationalization of industrial structure has long-term and short-term negative spatial spillover effects on haze pollution, but they are not significant. The upgrading of industrial structure has long-term and short-term negative spatial spillover effects on haze pollution at a $1 \%$ significant level. In a word, the rationalization and upgrading of the industrial structure of the surrounding cities can restrain the local haze pollution from the long-term or short-term perspective. Considering that the rationalization of industrial structure of adjacent cities has no significant impact on local haze emission reduction, this may be because the industrial structure of adjacent cities is not very reasonable, and the radiation effect on the rationalization of local industrial structure is not obvious. Combined with the results of spatial direct effect, the Yangtze River delta needs to build a more reasonable regional industrial structure, strengthen the upgrading of traditional enterprises, improve the level of industrial technology, promote the upgrading of industrial structure, and give full play to the role of restraining haze pollution through the rationalization and upgrading of industrial structure.

In addition, we find that, in the dynamic model, the long-term spatial spillover effect is smaller than the short-term spatial spillover effect, which indicates that, in the shortterm, the impact of resource transfer, industrial transfer, and economic flow between adjacent regions on local haze pollution is more significant, but, in the long run, this impact can not fundamentally improve local air quality. Therefore, in the long run, in order to reduce regional haze pollution and improve air quality, local governments should focus on controlling local factors affecting haze pollution and strengthen joint prevention and control combined with inter city factors.

Table 9. Spatial spillover effects.

\begin{tabular}{llll}
\hline Variables & Static Long-Term & Dynamic Long-Term & Dynamic Short-Term \\
\hline RS & $-0.0044^{* * *}$ & -0.0001 & -0.0002 \\
US & $-3.9964^{* * *}$ & $-0.6665^{* * *}$ & $-1.6586^{* * *}$ \\
$\operatorname{lnGDP}$ & $-17.8266^{* * *}$ & $-1.7999^{* * *}$ & $-7.1088^{* * *}$ \\
$\operatorname{lnGDP2}$ & $0.7738^{* * *}$ & $0.0816^{* * *}$ & $0.3316^{* * *}$ \\
$\operatorname{lnSIZE}$ & $-1.7990^{* * *}$ & $-0.0248^{*}$ & $-0.0768^{*}$ \\
$\operatorname{lnFDI}$ & $1.6800^{* * *}$ & $0.0377^{*}$ & $0.1211^{* * *}$ \\
$\operatorname{lnPU}$ & $4.5951^{* * *}$ & $0.1542^{* * *}$ & $0.5217^{* * *}$ \\
\hline
\end{tabular}

\subsection{Robustness Check}

The spatial economic geography nested matrix in model (3) and (4) is replaced by the geo economic distance matrix, and the robustness test is conducted to verify our findings. The test results are shown in Tables 10-12. Table 10 is the parameter estimation of SDM. The results show that the rationalization and upgrading coefficient of industrial structure in the static model are significantly negative at the level of $1 \%$, while it is significantly positive at the level of $1 \%$ in the dynamic model. Table 11 is the direct effect estimation of $\mathrm{SDM}$. In the long-term direct effect estimation results, the rationalization and upgrading coefficients of industrial structure in both models are significantly negative at the level of $1 \%$. In the short-term direct effect estimation results, the rationalization coefficient of 
industrial structure is significantly positive at the level of $1 \%$, and the upgrading coefficient of industrial structure is significantly negative at the level of $1 \%$. Table 12 is the estimation of spatial spillover effect of SDM. No matter from the long-term or short-term perspective, the rationalization and upgrading coefficient of industrial structure in the two models are significantly negative at the level of $1 \%$. We find that the robustness test results are similar to the above empirical results. Therefore, it can be considered that the model selected in this paper is robust.

Table 10. SDM parameter estimation.

\begin{tabular}{lll}
\hline Variables & Static & Dynamic \\
\hline RS & $-0.0002^{* * *}$ & $0.0028^{* * *}$ \\
US & $-0.1657^{* * *}$ & $1.2873^{* * *}$ \\
lnGDP & $-0.5568^{* * *}$ & $-0.6564^{* * *}$ \\
lnGDP2 & $0.0277^{* * *}$ & $0.0219^{* * *}$ \\
lnSIZE & $-0.0031^{* * *}$ & $0.1592^{* * *}$ \\
lnFDI & $0.0276^{* * *}$ & $-0.0429^{* * *}$ \\
lnPU & $0.1085^{* * *}$ & $-0.6131^{* * *}$ \\
lnPM(-1) & & $0.7959^{* * *}$ \\
WRS & $-0.0015^{* * *}$ & $0.0156^{* * *}$ \\
WUS & $-0.9241^{* * *}$ & $27.4241^{* * *}$ \\
WlnGDP & $-5.0893^{* * *}$ & $88.0768^{* * *}$ \\
WlnGDP2 & $0.2360^{* * *}$ & $-4.0326^{* * *}$ \\
WlnSIZE & $-0.6415^{* * *}$ & $8.0867^{* * *}$ \\
WlnFDI & $0.5355^{* * *}$ & $-5.9126^{* * *}$ \\
WlnPU & $0.7918^{* * *}$ & $-21.9354^{* * *}$ \\
Spatial rho & $0.8544^{* * *}$ & $44.7580^{* * *}$ \\
sigma2_e & $0.0110^{* * *}$ & $-0.0263^{* * *}$ \\
\hline Note: *** $p<0.01$. & &
\end{tabular}

Table 11. Spatial direct effect.

\begin{tabular}{llll}
\hline Variables & Static Long-Term & Dynamic Long-Term & Dynamic Short-Term \\
\hline RS & $-0.0004^{* * *}$ & $-0.0001^{* * *}$ & $0.0002^{* * *}$ \\
US & $-0.3411^{* * *}$ & $-0.4677^{* * *}$ & $-0.2843^{* * *}$ \\
$\operatorname{lnGDP}$ & $-1.4626^{* * *}$ & $-1.9936^{* * *}$ & $-1.7407^{* * * *}$ \\
$\operatorname{lnGDP2}$ & $0.0699^{* * *}$ & $0.0904^{* * *}$ & $0.0783^{* * *}$ \\
$\operatorname{lnSIZE}$ & $-0.1087^{* * *}$ & $-0.1604^{* * *}$ & $-0.1218^{* * *}$ \\
$\operatorname{lnFDI}$ & $0.1196^{* * *}$ & $0.1248^{* * *}$ & $0.1018^{* * *}$ \\
$\operatorname{lnPU}$ & $0.2548^{* * *}$ & $0.4169^{* * *}$ & $0.2994^{* * *}$ \\
\hline
\end{tabular}
Note: ${ }^{* * *} p<0.01$.

Table 12. Spatial spillover effects.

\begin{tabular}{llll}
\hline Variables & Static Long-Term & Dynamic Long-Term & Dynamic Short-Term \\
\hline RS & $-0.0114^{* * *}$ & $-0.0004^{* * *}$ & $-0.0006^{* * *}$ \\
US & $-7.4585^{* * *}$ & $-0.1769^{* * *}$ & $-0.3720^{* * *}$ \\
lnGDP & $-39.2270^{* * *}$ & $0.0314^{* *}$ & $-0.2573^{* * *}$ \\
$\operatorname{lnGDP2}$ & $1.8297^{* * *}$ & $-0.0004^{* * *}$ & $0.0134^{* * *}$ \\
$\operatorname{lnSIZE}$ & $-4.5143^{* * *}$ & $-0.0246^{* * *}$ & $-0.0665^{* * *}$ \\
$\ln \mathrm{FDI}$ & $3.9269^{* * *}$ & $0.0088^{* * *}$ & $0.0343^{* * *}$ \\
$\ln P U$ & $6.2595^{* * *}$ & $0.0893^{* * *}$ & $0.2159^{* * *}$ \\
\hline Note: ${ }^{* * *} p<0.01^{* *} p<0.05$. & &
\end{tabular}




\section{Discussion}

Compared with previous studies, the index of industrial structure selected in this study is rationalization and upgrading of industrial structure. Previous studies mostly selected the proportion of secondary industry in GDP as the index of industrial structure [5,9]. Although the index is different, the result is similar to those of previous studies [29]. They all show that industrial structure is related to haze pollution. Furthermore, we find that rationalization and upgrading of industrial structure have a negative correlation with haze pollution. Therefore, when the rationalization and upgrading of industrial structure is used as the measurement index, the analysis of the impact of industrial structure on haze pollution could be more comprehensive.

Compared with the previous study [11,30], this study uses the SDM method to consider the impact of industrial structure on haze pollution from the perspective of space. Although the research methods and perspectives are different, the results are not completely consistent [31]. Not only do the rationalization and upgrading of industrial structure have an inhibitory effect on local haze pollution, but also the industrial structure has a negative spatial spillover effect on haze pollution. The industrial structure of adjacent areas has an inhibitory effect on local haze pollution. Therefore, when considering the impact of industrial structure on haze pollution, we can not ignore the spatial spillover effect of industrial structure.

Compared with the short term and long term, this study finds that the effects of rationalization and upgrading of industrial structure on haze pollution are different. The negative spatial spillover effect of rationalization and upgrading of industrial structure on haze pollution is more significant in the long term. Therefore, in the treatment of haze pollution, according to the actual needs of different regions, different strategies are selected.

\section{Conclusions and Suggestions}

Based on the panel data of 41 cities in the Yangtze River Delta from 2002 to 2016, the spatial effects of industrial structure optimization on haze pollution were analyzed from static and dynamic perspectives using SDM. This study finds that haze pollution in Yangtze River Delta has a significant positive spatial spillover effect and time lag effect; Rationalization and upgrading of industrial structure have long-term and short-term direct effects and spatial spillover effects on haze pollution. In static and dynamic models, they have significant negative spatial spillover effects on haze pollution. There is a positive " $U$ " curve relationship between economic growth and haze pollution; FDI and population density have a positive direct effect and spatial spillover effect on haze pollution; the number of Industrial Enterprises above a designated size has a negative direct effect and spatial spillover effect on haze pollution.

These findings indicate that the haze pollution in the surrounding cities is serious, and it could be serious in some areas, or the haze pollution in a city last year is serious, and it could be serious in the next few years, such as Nantong, Lianyungang, and other cities; recently, the haze level is still light pollution. In the long run, the rationalization and upgrading of industrial structure is conducive to the suppression of haze pollution in local and adjacent areas; excessive pursuit of economic growth aggravates haze pollution; and the increase of FDI and population density could promote the haze pollution in local and adjacent areas, such as Nanjing, Changzhou, Wuxi, and other cities with high FDI and population density, and the Urban Haze pollution could be more serious; the increase in the number of Industrial Enterprises above designated size could help to reduce haze pollution.

Based on the above conclusions, in order to reduce the urban haze pollution, some suggestions are given as follows:

Enhancing people's understanding of environmental protection and urging people to protect the environment will help to reduce emissions. In rural areas, publicity and education prohibit burning straw and other environmental pollution behavior. At the same time, local governments could also actively communicate, strengthen cooperation, increase investment in haze control, timely monitor and control haze, and strengthen joint 
prevention and control of haze pollution among cities, which could reduce the impact of current haze on future urban air quality. Finally, the construction of green buffer zones around cities with serious haze pollution, such as Wuxi, Xuancheng, Huzhou, and Jiaxing, is conducive to reducing PM2.5 spillover to surrounding cities.

Further optimization and upgrading of industrial structure in the Yangtze River Delta region could help to reduce haze pollution. The government's reasonable guidance of national industrial policies, adjustment of unreasonable industrial structure, promotion of rational allocation of production factors, coordinated development of various industries, and avoidance of overcapacity are conducive to control the rationalization of industrial structure, so as to reduce haze pollution. In terms of upgrading the industrial structure, on the one hand, we could decrease the proportion of the secondary industry. Encouraging enterprises to actively eliminate backward production capacity, upgrading technology and equipment, and rewarding some ultra-low emission enterprises could help to reduce the proportion of the secondary industry. These methods could be used in cities such as Ma'anshan and Huainan and other cities. On the other hand, we could increase the proportion of the tertiary industry. Expanding the emerging producer services market could help reduce haze pollution.

Maintaining high-quality economic development and reducing the dependence of the Yangtze River Delta on high pollution heavy industry could help to reduce haze pollution. Supporting and encouraging the development of digital economy could also be conducive to the control of haze pollution. For foreign direct investment, the government could raise the standards of environmental protection regulations and refuse high polluting foreign enterprises to enter, which could also help to reduce haze pollution. Strengthening the control of population density in the Yangtze River Delta could encourage the population of Shanghai, Hangzhou, Nanjing, and other cities to migrate to the surrounding cities, which could help to reduce haze pollution. Giving subsidies to large industrial enterprises such as demonstration enterprises, encouraging enterprises to continuously innovate, and developing high and new technologies could reduce haze pollution.

These suggestions can be summarized in Table 13.

Table 13. Suggestions.

\begin{tabular}{ll}
\hline Factors & Suggestions \\
\hline PM2.5 & $\begin{array}{l}\text { Enhance people's awareness of environmental protection, urge people to protect the environment } \\
\text { Strengthen the joint prevention and control of haze pollution among cities } \\
\text { Establish green buffer zones around cities with serious haze pollution }\end{array}$ \\
\hline Rationalization of industrial structure & $\begin{array}{l}\text { Guide the national industrial policy reasonably and adjust the unreasonable industrial structure } \\
\text { Upgrading of industrial structure }\end{array}$ \\
\hline GDP & $\begin{array}{l}\text { Decrease the secondary industry } \\
\text { Increase the tertiary industry }\end{array}$ \\
\hline Foreign direct investment & Maintain high-quality economic development \\
\hline Industrial enterprises meeting the requirements of a certain scale & Encourage large-scale enterprises to continuously innovate and develop high and new technologies \\
\hline Population density & Strengthen the control of population density in the Yangtze River Delta \\
\hline
\end{tabular}

Author Contributions: S.J. designed this research and revised the manuscript; L.W. collected and analyzed the data, and wrote the paper. H.X. provided suggestions. All authors have read and agreed to the published version of the manuscript.

Funding: This project is supported by the National Natural Science Foundation of China (Grant No. 51876081).

Institutional Review Board Statement: Not applicable.

Informed Consent Statement: Not applicable.

Data Availability Statement: Not applicable.

Conflicts of Interest: The authors declare no conflict of interest. 


\section{References}

1. Gai, L. Discussion on the causes of haze weather and its prevention and control measures. Resour. Inf. Eng. 2017, 32, 187-188.

2. Li, L.; Liu, X.; Ge, J.; Chu, X.; Wang, J. Regional differences in spatial spillover and hysteresis effects: A theoretical and empirical study of environmental regulations on haze pollution in China. J. Clean. Prod. 2019, 230, 1096-1110. [CrossRef]

3. Chen, S.; Zhang, Y.; Zhang, Y.; Liu, Z. The relationship between industrial restructuring and China's regional haze pollution: A spatial spillover perspective. J. Clean. Prod. 2019, 239, 115808.1-115808.11. [CrossRef]

4. Fang, Y. Industrial structure, urbanization and haze pollution. Resour. Conserv. Environ. Prot. 2016, 3, 41.

5. Zheng, Y.; Peng, J.; Xiao, J.; Su, P.; Li, S. Industrial structure transformation and provincial heterogeneity characteristics evolution of air pollution: Evidence of a threshold effect from China. Atmos. Pollut. Res. 2020, 11, 598-609. [CrossRef]

6. Leng, Y.; Du, S. Industrial structure, urbanization and haze pollution. China Sci. Technol. Forum 2015, 31, 49-55.

7. Zhang, X.; Ma, D. Study on the interaction between coal consumption, industrial structure and haze pollution in Henan Province. Coal Eng. 2020, 52, 194-199.

8. Wang, S.; Liu, T. Empirical Study on the influence of urban industrial structure on haze in Anhui Province. J. Shandong Agric. Eng. Univ. 2019, 36, 27-33.

9. Hao, Y.; Zheng, S.; Zhao, M.; Wu, H.; Guo, Y.; Li, Y. Reexamining the relationships among urbanization, industrial structure, and environmental pollution in China-New evidence using the dynamic threshold panel model. Energy Rep. 2020, 6, 28-39. [CrossRef]

10. Zhan, W. Study on Temporal and Spatial Distribution Characteristics and Influencing Factors of Haze Pollution in China. Ph.D. Thesis, University of Science and Technology of China, Hefei, China, 2017.

11. Zhu, M.; Wu, Q.; Zhang, H.; Chen, Z. Threshold effect of rationalization of industrial structure on air quality in Shanxi Province. J. Resour. Ecol. 2020, 011, 206-212.

12. $\mathrm{Xu}, \mathrm{Y}$. Research on the Impact of Industrial Structure Change on PM2.5 Spatiotemporal Process of Five Typical Economic Cities in China and Construction of Simulation Platform. Ph.D. Thesis, Yunnan Normal University, Kunming, China, 2017.

13. Cheng, Z.; Li, L.; Liu, J. The spatial correlation and interaction between environmental regulation and foreign direct investment. J. Regul. Econ. 2018, 54, 124-146. [CrossRef]

14. Elhorst, J.P. Spatial Econometrics: From Cross-Sectional Data to Spatial Panels; Physica-Verlag HD: Heidelberg, Germany, 2014.

15. Wang, M. Spatial research on Influencing Factors of haze economic structure in China. Financ. Econ. 2018, 37, 30-31.

16. Han, N. Spatial econometric study on China's economic growth, industrial structure and environmental pollution. Environ. Eng. 2016, 34, 155-159.

17. Wang, J.; Liu, S. Financial development, urbanization and haze pollution-Based on the spatial econometric analysis of five provinces in Northwest China. Ind. Technol. Econ. 2019, 38, 77-86.

18. Hui, Y.; Mao, P.; Dai, H. Empirical analysis on spatial distribution and influencing factors of haze pollution in Hebei Province. Econ. Manag. 2018, 32, 65-71.

19. LeSage, J.; Pace, K. Introduction to Spatial Econometrics; CRC Press: Boca Raton, FL, USA, 2009; p. 376.

20. Fan, Q.; Yang, S.; Liu, S. Asymmetrically Spatial Effects of Urban Scale and Agglomeration on Haze Pollution in China. Int. J. Environ. Res. Public Health 2019, 16, 4936. [CrossRef] [PubMed]

21. Yang, X.; Feng, L.; Wei, P. PM2.5 and its harm. Front. Sci. 2012, 6, 22-31.

22. Wang, H.; Zeng, Q.; Sun, R. Progress in Pathogenesis of PM2.5; Chinese Society of Integrated Traditional Chinese and Western Medicine; Shandong Society of Integrated Traditional Chinese and Western Medicine: Jinan, China, 2017.

23. Man, Y.; Yaping, H.; Huanfeng, S.; Tongwen, L. Effects of urban form on haze pollution in China: Spatial regression analysis based on PM 2.5 remote sensing data. Appl. Geogr. 2018, 98, 215-223.

24. Van Donkelaar, A.; Martin, R.; Brauer, M. Global Estimates of Fine Particulate Matter using a Combined Geophysical-Statistical Method with Information from Satellites, Models, and Monitors. Environ. Sci. Technol. 2016, 50, 3762-3772. [CrossRef]

25. Stern, D.I.; Van Dijk, J. Economic growth and global particulate pollution concentrations. Clim. Chang. 2017, 142, 391-406. [CrossRef]

26. Grossman, G.M.; Krueger, A.B. Economic Growth and the Environment. Q. J. Econ. 1995, 110, 353-377. [CrossRef]

27. Agarwal, N.; Milner, C.; Riano, A. Credit constraints and spillovers from foreign firms in China. J. Bank. Financ. 2014, 48, 261-275. [CrossRef]

28. Cheng, Z.; Li, L.; Liu, J. Identifying the spatial effects and driving factors of urban PM2.5 pollution in China. Ecol. Indic. 2017, 82, 61-75. [CrossRef]

29. Liu, X. Spatiotemporal differentiation, dynamic evolution and impact mechanism of Urban Haze pollution in China. J. Southwest Univ. Natl. (Humanit. Soc. Sci. Ed.) 2019, 40, 102-117.

30. Zhu, L.; Li, T.; Ma, L.; Liu, Z. The impact of industrial restructuring on haze pollution: An Empirical Study Based on Beijing Tianjin Hebei Urban Agglomeration in China. Ecol. Econ. 2018, 34, 141-148.

31. Lei, Y.; Zheng, M.; Sun, J. New urbanization, industrial structure adjustment and haze control based on the dual perspective of 112 key environmental protection cities. Ind. Technol. Econ. 2019, 38, 22-33. 